\title{
Determination of Temperature Zoning for the Great Lakes Region of Africa Based on Superpave System
}

\author{
Mukunde Ronald \\ rmm78@mail.aub.edu \\ American University of Beirut, Beirut, Lebanon \\ Ghassan Chehab \\ gc06@aub.edu.lb \\ American University of Beirut, Beirut, Lebanon \\ Mohammad Nour Fakhreddine \\ mff17@mail.aub.edu \\ American University of Beirut, Beirut, Lebanon
}

\begin{abstract}
Majority of the countries in the Great Lakes region of Africa still rely on the traditional Penetration grading approach for characterizing asphalt binder, as opposed to the more recent and reliable approach of SuperPave (Superior Performing Asphalt Pavements). This paper outlines the steps and criteria of selecting Performance Grade (PG) of bitumen to be used in selected countries of the Great Lakes region, based on the SuperPave approach. In Superpave, high-temperature (HT) Performance Grade required for a given region of project is determined based on a rutting damage model. HT equation is a function of layer thickness, climatic conditions, and latitude of the site (Mohseni et al, 2005); whereas, Low-temperature (LT) Performance Grade is selected using an algorithm developed from LTPP climatic data, and that relates the minimum pavement temperature to minimum air temperature, latitude, and depth (Mohseni, 1998). Study of climatic conditions of selected countries (Uganda, Kenya and Tanzania) in the great lakes region shows that the maximum pavement design temperature is $64{ }^{\circ} \mathrm{C}$, while the minimum pavement design temperature is $-10^{\circ} \mathrm{C}$. Further, the temperature zoning is distributed into three geographical areas, namely PG 64-10, PG 58-10 and PG 52-10 according to the collected and studied data.
\end{abstract}

Keywords: Strategic highway research program (SHRP); Superior performance asphalt pavements (SUPERPAVE); Long term pavement performance (LTPP); Performance grade (PG); Great lakes region of Africa

\section{INTRODUCTION}

Super pave binder specification is based on the performance of asphalt pavement, which is the main difference between this system and other earlier approaches such as Penetration and Viscosity grading (Asphalt institute, 2003). The physical and mechanical properties requirements of asphalt binders are fixed for all performance grades, but in the Superpave method, the maximum and minimum temperatures at which the binder shall meet the requirements are the basis of various grades. AASHTO M320 contains a listing of the more commonly used performance grades (PG), but the PG grades are not limited to those given classifications because the specification temperatures are unlimited (Azari 
et al, 2003). The high and low temperatures extended as far as necessary in the standard six increments. This paper explains the steps and criteria of selecting performance grade (PG) with reference to the Strategic Highway Research Program (SHRP) Specification and determination of the Great Lakes of Africa Temperature Zoning. The currently used Penetration grading in this region is empirical and suffers the limitation of accuracy in determining the full effects of variations in environmental and loading conditions on the pavement performance. Registered historical temperature data for ten years was obtained from various weather stations to cover different regions of the selected countries. The selection of performance grade based on SHRP specifications includes three important factors which are: historical temperature data, traffic conditions, and the desired reliability factor. The desired reliability and historical temperature data are of high importance in selecting the temperature zone for the selected country or region. Although other factors such as the traffic condition should be considered when selecting binder grade for the asphalt mix, the Superpave system facilitates the knowledge of the base PG of the asphalt binder to be used in the project area directly from the temperature zoning map.

\section{METHODOLOGY}

\subsection{High pavement design temperature}

SHRP developed two models for determining high pavement temperature for PG grading purposes; one based on the rutting damage concept (the rutting damage model) and the other based on adjusting the PG with depth into the pavement (the LTPP High pavement temperature model). The latter was used in this study and is a function of air temperature, latitude and depth (Mohseni et al, 2005) as shown in Equation 1.

$\mathrm{T}_{\text {H.pav }}=54.32+0.78 \mathrm{~T}_{\text {air }}-0.0025 \mathrm{Lat}^{2}-15.14 \log (\mathrm{H}+25)-\mathrm{Z}\left(9+0.61 \sigma_{\text {Tair }}^{2}{ }^{0.5} \ldots \ldots\right.$

Where,

$\mathbf{T}_{\text {H.pav }}=$ High pavement design temperature.

$\mathbf{T}_{\text {air }}=$ Average seven-day average high air temperature, ${ }^{\circ} \mathrm{C}$.

Lat $=$ The Geographical latitude of the project.

H $=$ Depth to surface, $\mathrm{mm}$.

$\boldsymbol{\sigma}_{\mathrm{T} \text { air }}^{2}=$ Standard deviation of the mean low air temperature, ${ }^{\circ} \mathrm{C}$.

$\mathbf{Z}^{\mathbf{T} \text { air }}=$ Standard normal distribution value 2.055 for $98 \%$ reliability.

\subsection{Low pavement design temperature}

Low-temperature (LT) performance grade is selected using the algorithm developed from LTPP climatic data. LT algorithm relates minimum pavement temperature to minimum air temperature, latitude, and depth (Mohseni, 1993) as shown in Equation 2.

$$
\begin{aligned}
& \mathrm{T}_{\mathrm{L} \text {.pav }}=-\mathbf{1 . 5 6}+0.72 \mathrm{~T}_{\text {air }}-0.004 \mathrm{Lat}^{2}+6.26 \log (\mathrm{H}+25)-\mathrm{Z}\left(4.4+0.52 \sigma_{\mathrm{T} \text { air }}^{2}\right)^{0.5} \ldots \ldots(2) \\
& \text { Where: } \\
& \mathrm{T}_{\text {L.pav }}=\text { Low pavement temperature at surface, }{ }^{\circ} \mathrm{C} . \\
& \mathrm{T}_{\text {air }}=\text { Low air temperature, }{ }^{\circ} \mathrm{C} .
\end{aligned}
$$




\section{RESULTS}

The mean and standard deviation for maximum and minimum air temperatures during the specified period (ten years) for all the meteorological stations representing all the regions in the Great Lakes region are tabulated in Tables 1 to 3.

Table 1: The mean and standard deviations for high and low air temperatures in Uganda

\begin{tabular}{|c|c|c|c|c|c|c|c|}
\hline \multirow[t]{2}{*}{ Region } & \multirow[t]{2}{*}{ Station } & \multicolumn{2}{|c|}{ Mean } & \multicolumn{2}{|c|}{ Standard deviation (sd) } & \multicolumn{2}{|c|}{ +2 sd (98\% reliability) } \\
\hline & & Highest ${ }^{\circ} \mathrm{C}$ & Lowest ${ }^{\circ} \mathrm{C}$ & Highest ${ }^{\circ} \mathrm{C}$ & Lowest ${ }^{\circ} \mathrm{C}$ & Highest ${ }^{\circ} \mathrm{C}$ & Lowest ${ }^{\circ} \mathbf{C}$ \\
\hline \multirow{4}{*}{ North } & Gulu & 34.56 & 16.67 & 1.27 & 0.52 & 37.09 & 15.63 \\
\hline & Lira & 34.11 & 16.22 & 1.14 & 0.63 & 36.38 & 14.96 \\
\hline & Moroto & 32.00 & 16.89 & 0.88 & 0.63 & 33.75 & 15.62 \\
\hline & Arua & 33.78 & 16.78 & 0.92 & 0.67 & 35.62 & 15.43 \\
\hline \multirow{5}{*}{ West } & Kabale & 27.44 & 14.00 & 1.42 & 0.47 & 30.28 & 13.06 \\
\hline & Mbarara & 27.56 & 14.00 & 1.26 & 0.47 & 30.09 & 13.06 \\
\hline & Kasese & 27.78 & 13.11 & 0.99 & 0.95 & 29.77 & 11.21 \\
\hline & Fort Portal & 27.78 & 13.11 & 0.99 & 0.95 & 29.77 & 11.21 \\
\hline & Hoima & 33.22 & 16.22 & 0.82 & 0.63 & 34.87 & 14.96 \\
\hline \multirow{7}{*}{ East \& Central } & Entebbe & 25.11 & 17.33 & 0.79 & 1.48 & 26.69 & 14.38 \\
\hline & Kampala & 28.22 & 15.44 & 1.03 & 1.07 & 30.29 & 13.29 \\
\hline & Jinja & 29.89 & 14.44 & 1.62 & 1.08 & 33.13 & 12.28 \\
\hline & Kalangala & 25.11 & 17.33 & 0.79 & 1.48 & 26.69 & 14.38 \\
\hline & Tororo & 31.33 & 14.67 & 1.07 & 0.67 & 33.48 & 13.32 \\
\hline & Mbale & 29.78 & 14.11 & 0.94 & 0.42 & 31.66 & 13.27 \\
\hline & Soroti & 34.33 & 16.11 & 1.27 & 0.74 & 36.87 & 14.64 \\
\hline
\end{tabular}

Table 2: The mean and standard deviations for high and low air temperatures in Kenya

\begin{tabular}{|c|c|c|c|c|c|c|c|}
\hline \multirow[t]{2}{*}{ Region } & \multirow[t]{2}{*}{ Station } & \multicolumn{2}{|c|}{ Mean } & \multicolumn{2}{|c|}{ Standard deviation (sd) } & \multicolumn{2}{|c|}{ +2 sd ( $98 \%$ reliability) } \\
\hline & & Highest ${ }^{\circ} \mathrm{C}$ & Lowest $^{\circ} \mathrm{C}$ & Highest ${ }^{\circ} \mathrm{C}$ & Lowest ${ }^{\circ} \mathrm{C}$ & Highest $^{\circ} \mathrm{C}$ & Lowest $^{\circ} \mathrm{C}$ \\
\hline Central & Nairobi & 27.50 & 12.10 & 1.27 & 0.57 & 30.04 & 10.96 \\
\hline Coast & Mombasa & 31.70 & 22.00 & 0.82 & 0.00 & 33.35 & 22.00 \\
\hline North East & Wajir & 36.40 & 22.40 & 0.52 & 0.70 & 37.43 & 21.00 \\
\hline East & Meru & 24.40 & 11.50 & 0.70 & 1.35 & 25.80 & 8.79 \\
\hline Rift valley & Nakuru & 25.30 & 8.90 & 1.25 & 0.74 & 27.80 & 7.42 \\
\hline West & Kisumu & 30.00 & 14.10 & 1.15 & 0.57 & 32.31 & 12.96 \\
\hline
\end{tabular}

Table 3: The mean and standard deviations for high and low air temperatures in Tanzania

\begin{tabular}{|c|c|c|c|c|c|c|c|}
\hline \multirow[t]{2}{*}{ Region } & \multirow[t]{2}{*}{ Station } & \multicolumn{2}{|c|}{ Mean } & \multicolumn{2}{|c|}{ Standard deviation (sd) } & \multicolumn{2}{|c|}{+2 sd ( $98 \%$ reliability) } \\
\hline & & Highest $^{\circ} \mathrm{C}$ & Lowest ${ }^{\circ} \mathrm{C}$ & Highest $^{\circ} \mathrm{C}$ & Lowest $^{\circ} \mathrm{C}$ & Highest ${ }^{\circ} \mathrm{C}$ & Lowest ${ }^{\circ} \mathrm{C}$ \\
\hline Costal & $\begin{array}{l}\text { Dar-es- } \\
\text { Salaam }\end{array}$ & 31.00 & 21.20 & 0.57 & 0.42 & 32.14 & 19.94 \\
\hline Central & Dodoma & 32.10 & 14.00 & 1.29 & 0.82 & 34.67 & 11.55 \\
\hline North & Arusha & 29.90 & 13.20 & 1.20 & 0.63 & 32.29 & 11.30 \\
\hline West & Kigoma & 26.10 & 19.40 & 1.20 & 1.17 & 28.49 & 15.88 \\
\hline
\end{tabular}


SHRP performance-based binder and mixture specifications are developed based on the tests related to the pavement performance under different climatic conditions. Equation 1 is used to transfer the highest air temperature to high design pavement temperature. Similarly, Equation 2 is used to determine the low design pavement temperature. The results of design pavement temperatures were used to determine the PG grades for different regions of selected countries in the Great lakes region of Africa.

\subsection{East African Temperature Zoning Map}

The Great Lakes region of Africa consists of seven countries, Uganda, Kenya, Tanzania, Rwanda, Burundi, Malawi and the Democratic Republic of Congo. The region experiences tropical climate which is characterized by high precipitation throughout the year. Moreover, the air temperatures rarely fall below $10^{\circ} \mathrm{C}$ yet do not go beyond 37 ${ }^{\circ} \mathrm{C}$. In this study, three countries were selected as representatives of the region due to their strategic location and varying climatic conditions. Twenty-six weather stations are considered to cover the selected states. As a result of this study, the East African Temperature Zoning map was established, to serve as reference for asphalt PG grade selection in this region according to the Superpave system. The hottest areas reported high pavement design temperature not more than $64^{\circ} \mathrm{C}$ and the rest reported high design temperatures between 52 and $58{ }^{\circ} \mathrm{C}$.

The following assumptions were used to establish the East African Temperature Zoning Map:

I. The station in any region should be taken as a reference for the whole region;

II. If there are many stations in one region, then the high recorded reading is used; and III. The regional/ provincial borders are used as separators between zones.

The results of fourteen (14) regions for the three selected countries in the Great Lakes region of Africa are illustrated in Figures 1 to $\mathbf{4}$ below;

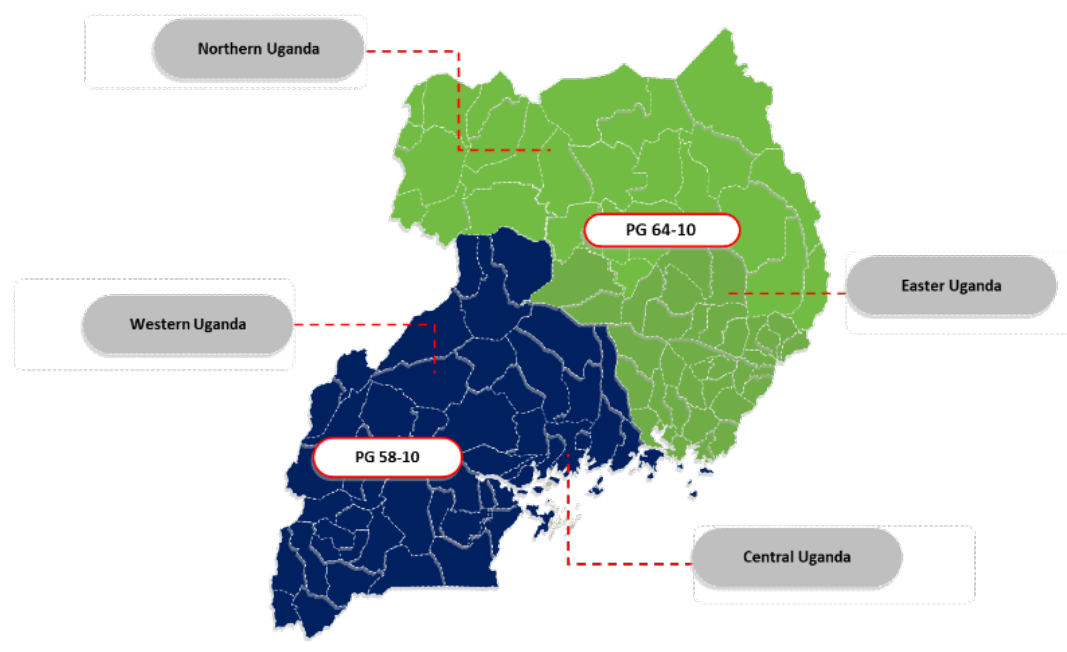

Figure 1: Uganda's PG zoning map 


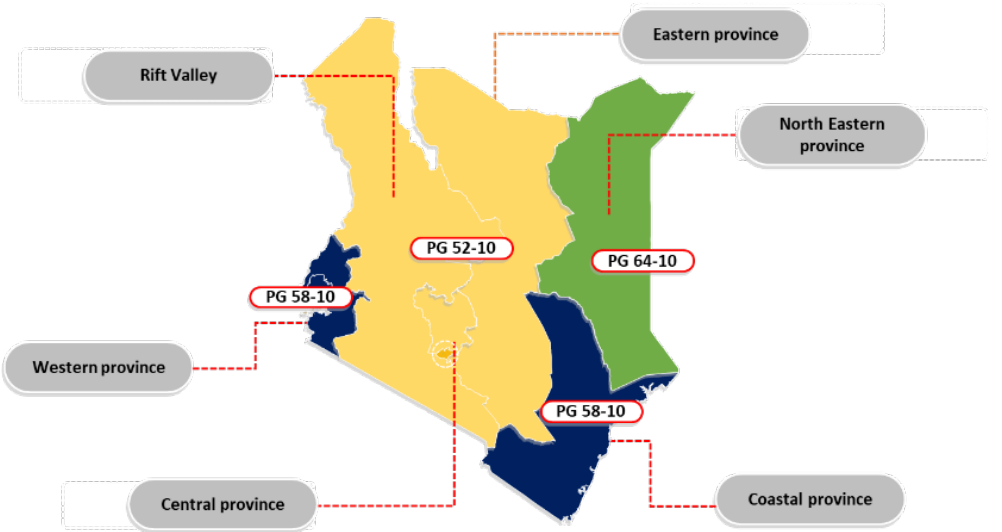

Figure 2: Kenya's PG zoning map

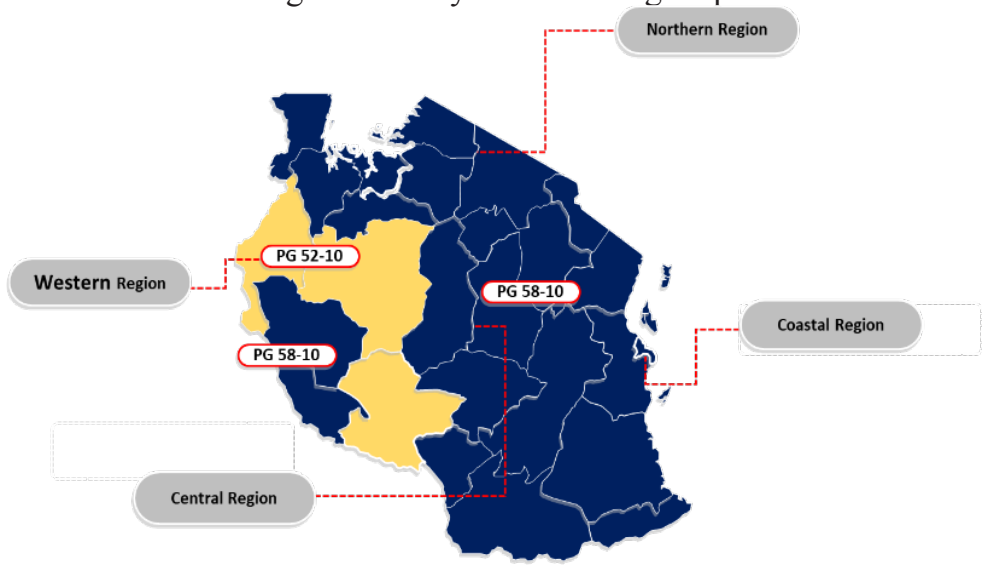

Figure 3: Tanzania's PG zoning map

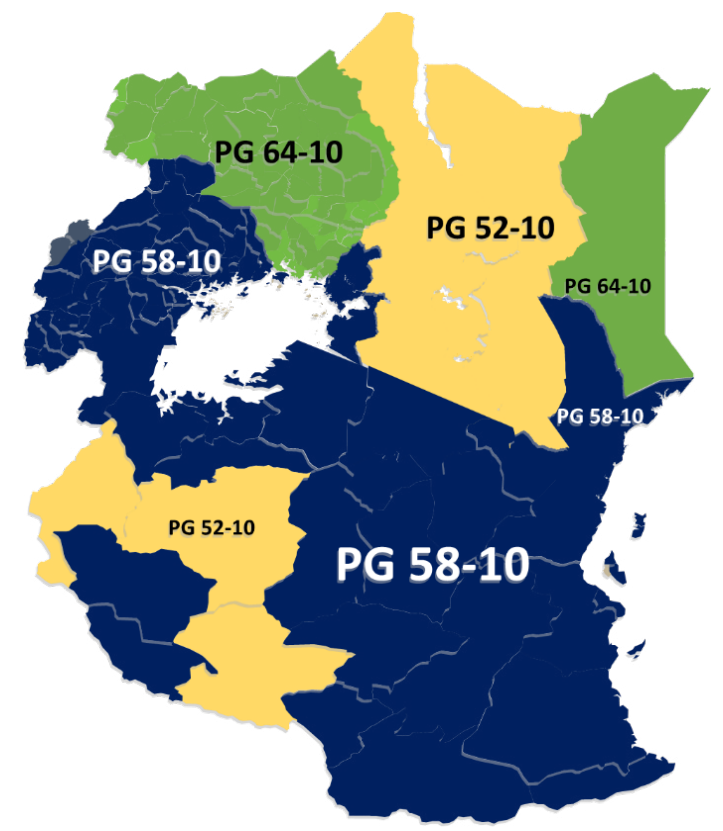

Figure 4: East Africa's PG zoning map 


\subsection{Incorporating Effects of Traffic Conditions}

Final selection of required Performance Grade (PG) for a given project depends on adjusting the base binder grade selected according to climatic criteria to account for desired reliability and traffic conditions. Table 4 includes the Superpave specifications for high-temperature design grade adjustment (grade bump) based on traffic volume and speed. One major drawback is that SHRP does not provide any guidelines regarding the depth of the asphalt layer up to which this bumping should be applied (Chehab et al, 2019).

Table 4: Adjustment to the high-temperature grade of Binder based on traffic speed and traffic level

\begin{tabular}{|c|c|c|c|c|c|}
\hline \multicolumn{6}{|c|}{ Adjustment to Binder PG grade ${ }^{2}$} \\
\hline \multirow[b]{2}{*}{$\begin{array}{l}\text { Traffic loading rate } \\
\text { (design speed) }\end{array}$} & \multirow[b]{2}{*}{ Base Grade } & \multicolumn{4}{|c|}{ Design ESALs (millions) ${ }^{1}$} \\
\hline & & $<3$ & $3-10$ & $10-30$ & $>30$ \\
\hline \multirow{4}{*}{$\begin{array}{c}\text { Standing } \\
\text { (Av. Speed }<20 \mathrm{Km} / \mathrm{hr} \text {.) }\end{array}$} & 52 & 2 & 2 & 2 & 2 \\
\hline & 58 & 2 & 2 & 2 & 2 \\
\hline & 64 & 2 & 2 & 2 & 2 \\
\hline & 70 & 2 & 2 & 2 & 2 \\
\hline \multirow{4}{*}{$\begin{array}{c}\text { Slow } \\
\text { (Av. Speed } 20 \text { to } 70 \\
\mathrm{Km} / \mathrm{hr} \text {.) }\end{array}$} & 52 & 1 & 1 & 1 & $1^{(3)}$ \\
\hline & 58 & 1 & 1 & 1 & 1 \\
\hline & 64 & 1 & 1 & 1 & 1 \\
\hline & 70 & 1 & 1 & 1 & 1 \\
\hline \multirow{4}{*}{$\begin{array}{c}\text { Fast } \\
\text { (Av. Speed }>70 \mathrm{Km} / \mathrm{hr} \text {.) }\end{array}$} & 52 & - & - & - & 1 \\
\hline & 58 & - & - & - & 1 \\
\hline & 64 & - & - & - & 1 \\
\hline & 70 & $-(3)$ & - & - & 1 \\
\hline
\end{tabular}

1. Design ESALs is the anticipated project traffic level expected on the design lane over 20 years.

2. Increase the high-temperature grade by the number of grade equivalents indicated (one grade equivalent to $6^{\circ} \mathrm{C}$ ). The low-temperature grade is not adjusted.

3. Consideration should be given to increasing the high-temperature grade by one grade equivalent. Practically, performance graded binders stiffer than PG 82-XX should be avoided. In cases where the required adjustment to the high-temperature binder grade would result in a grade higher than a PG 82, consideration should be given to specifying a PG 82-XX and increasing the design ESALs by one level (e.g., 10 - 30 million increased to $>30$ million).

\section{CONCLUSION}

Based on the comprehensive collected data from the meteorological weather stations in selected Great Lakes region states and the analysis of the data based on the SHRP Superpave system procedure, the following conclusion can be stated:

1. The range of average lowest and highest air temperatures during the specified period is between $\left(8.06{ }^{\circ} \mathrm{C}\right.$ to $\left.18.52{ }^{\circ} \mathrm{C}\right)$ and $\left(24.40{ }^{\circ} \mathrm{C}\right.$ to $\left.36.41{ }^{\circ} \mathrm{C}\right)$ respectively.

2. Based on the weather data analysis, the maximum and minimum air temperatures registered are in North Eastern and the rift valley provinces of Kenya respectively.

3. The study also showed that the base maximum pavement design temperature is 64 ${ }^{\circ} \mathrm{C}$ and the conservative minimum pavement design temperature is $-10{ }^{\circ} \mathrm{C}$. 
4. The temperature zoning in the selected states is distributed into three zones which are PG 64-10, PG 58-10 and PG 52 -10.

5. The PG grade map acts as a reference for pavement design in the selected states. The design traffic conditions should be taken into consideration for pavement design in any of the regions, to know the need for improving the PG grade according to Table 4.

6. Further studies should be carried out for neighboring countries to establish the corresponding PG grades to be used in asphalt pavements.

\section{REFERENCES}

Asi, I. M. (2007). Performance evaluation of SUPERPAVE and Marshall asphalt mix designs to suite Jordan climatic and traffic conditions. Construction and Building Materials, 21(8), 1732-1740.

Asphalt Institute (Ed.) (2003). Performance graded asphalt binder specification and testing (No. 1). Asphalt Institute.

Azari, H., McCuen, R. H. \& Stuart, K. D. (2003). Optimum compaction temperature for modified binders. Journal of Transportation Engineering, 129(5), 531-537.

Chehab, G. R., Hamdar, Y. S., \& Haddad, A. J. (2019). Investigating High-Temperature PG Grade Adjustment Recommendations for Airfield Pavements. Transportation Research Record, 0361198119838259 .

Denneman, E. (2007). Application of locally developed pavement temperature prediction algorithms in performance grade (PG) binder selection.

Design, S. M. (1996). Superpave Series No. 2 (SP-2). Asphalt Institute, Lexington, KY.

Mohseni, A. (1998). LTPP Seasonal Asphalt Concrete (AC) Pavement Temperature Models, Report No. FHWA-RD-97-103, Federal Highway Administration, Washington, D.C.

Mohseni, A. Carpenter, S. H., \& D'Angelo, J. (2005). “Development of Superpave high temperature performance grade (PG) based on rutting damage (With Discussion and Closure)," Journal of the Association of Asphalt Paving Technologists, 74(1), pp. 197-254, The Association of Asphalt Paving Technologists, Lino Lakes, MN. 